\title{
A Trend Analysis of Junior High School Pupils' Performance in the Basic Education Certificate Examination (BECE) in Ghana
}

\author{
Regina Mawusi Nugba ${ }^{1}$, Frank Quansah ${ }^{2,}$, Francis Ankomah $^{1}$, Enoch Ewoenam Tsey ${ }^{1}$, \\ Vera Rosemary Ankoma-Sey ${ }^{3}$ \\ ${ }^{1}$ Department of Education and Psychology, University of Cape Coast, Cape Coast, Ghana \\ ${ }^{2}$ Department of Educational Foundations, University of Education, Winneba, Ghana \\ ${ }^{3}$ College of Distance Education, University of Cape Coast, Cape Coast, Ghana
}

\section{Email address:}

regina.nugba@ucc.edu.gh (R. M. Nugba),fquansah@uew.edu.gh (F. Quansah), francis.ankomah@stu.ucc.edu.gh (F. Ankomah), enoch.tsey@stu.ucc.edu.gh (E. E. Tsey), vankomah-Sey@ucc.edu.gh (V. R. Ankoma-Sey)

${ }^{*}$ Corresponding author

\section{To cite this article:}

Regina Mawusi Nugba, Frank Quansah, Francis Ankomah, Enoch Ewoenam Tsey, Vera Rosemary Ankoma-Sey. A Trend Analysis of Junior High School Pupils' Performance in the Basic Education Certificate Examination (BECE) in Ghana. International Journal of Elementary Education. Vol. 10, No. 3, 2021, pp. 79-86. doi: 10.11648/j.ijeedu.20211003.15

Received: August 10, 2021; Accepted: August 27, 2021; Published: September 6, 2021

\begin{abstract}
In recent times, parents and other stakeholders in the field of education have expressed worries regarding the poor performance of pupils in rural and public schools in the Basic Education Certificate Examination (BECE) compared to their counterparts in urban and private schools in Ghana. This study examines the performance trends of urban, rural, public and private Junior High Schools in the BECE over a 5-year period. The study made use of secondary data which reflected the indicators of pupils' performance in the BECE. The data obtained were analysed using percentages, frequency counts, and time-series graphs. The findings of this research showed that the proportion of pupils who passed the BECE in rural schools were less than those who passed in the urban schools in Ghana. It was further observed that although the performance trends for both public and private schools were not so different for 2016, 2017, and 2018, more pupils in public than private schools passed the BECE. Based on the findings, the Ministry of Education and all relevant stakeholders in the area of education are encouraged to ensure equitable distribution of resources in terms of infrastructure, teaching and learning resources, adequate and competent teachers to both urban and rural schools to promote the enhancement of pupils' performance in rural schools.
\end{abstract}

Keywords: Junior High School (JHS), Performance, Rural, Urban, Basic Education Certificate Examination (BECE)

\section{Introduction}

The success and growth of every nation depend substantially on the quality of education provided to its citizens [1]. This explains why Sustainable Development Goal 4 stresses equitable and inclusive quality education for all [2]. Basic education is the core of development and progress in modern societies. It is the level of education that develops the individual's capacity to read, write and calculate. In other words, basic education helps to eradicate illiteracy, which is one of the strongest predictors of poverty [3]. Thus, basic education is the only level of education that is available everywhere, both in developed and developing countries as well as in urban and rural areas [4]. This explains why basic education is the largest subsector of any education system and offers the unique opportunity to contribute to the transformation of societies through the education of young ones [5].

Access to education in Ghana is seen both as a fundamental human right and an essential element in the national development strategy in promoting growth and ensuring preparedness for a productive life. Ghana's 
aspiration to become a fully developed county rests, to a large extent, on her ability to improve educational access to the point where the population is highly educated to provide the human resource base for accelerated development [6]. According to the Ministry of Education of Ghana (MoE) [7], education at the primary level often emphasizes the importance of literacy, numeracy and problem-solving skills. Quality primary education also lays the foundation for inquiry, creativity, and innovation among individuals who have access to it. It is also important to emphasize that through primary education, the attribute of good citizenship is inculcated in children to enable them to participate in national development and for them to develop the skills and attitudes required for assimilating new knowledge [7]. The junior secondary school (JSS) in Ghana, now called junior high school (JHS) has also been planned to provide pupils with basic pre-technical, pre-vocational and scientific knowledge, while the senior secondary education (which is the next level of education after JHS education) is intended to reinforce the knowledge and skills acquired during basic education, as well as provide opportunities to help pupils develop different talents and skills [7-9].

Pupils who complete basic education in Ghana sit for a nationwide examination called Basic Education Certificate Examination (BECE) [9]. The basic education certificate is awarded to pupils who successfully pass the BECE after completion of the nine-year basic education programme. Candidates are graded based on their performance in the external examination (70\%) and school-based (internal) assessment (30\%) marks provided by the schools. A ninepoint scale (stanine in reversed form) is used in grading the candidates, with Grade 1 denoting the best performance and Grade 9, the poorest.

Education in Ghana, more especially, at the basic level, has witnessed a downward trend in terms of academic outcomes. According to available records from 2006 to 2016, over $3,669,138$ BECE candidates who sat for that examination out of which 1,562,270 (43\%) of them failed to make the required grades (i.e., those who had aggregates 30 and above) for progression to any secondary, technical or vocational school [10]. Also, in 2017, a total of 36,849 candidates (8\%) across the country were not placed into senior high school (SHS) because they scored Grade 9 in either English or Mathematics or both [11]. As a result of the failure, the MoE and Ghana Education Service (GES) instituted a re-sit policy for those who fail the BECE.

Previous studies have identified several factors which have contributed to the poor academic attainments by students. These factors include inadequate infrastructure, insufficient instructional materials, pupil absenteeism, parental noninvolvement, inconducive teaching and learning environment, teacher-related variables, among others [1219]. Despite the various attempts by educational stakeholders to improve the quality and accessibility of basic education for all pupils, obvious disparities in the provision of facilities for basic education in the country still exist. The most felt disparity in terms of urban and rural education is the infrastructural deficit in the rural schools. That is, pupils in the urban areas have many advantages over those in the rural areas in terms of infrastructure, teaching and learning resources, computers and access to the internet [18, 20]. Again, rural schools are often characterised by an inadequate number of teachers, poor classroom structures and, in some cases, schools are under trees. For the schools under trees, it becomes impossible to have lessons during rainy seasons and bad weather. Sadly enough, pupils in some rural areas study under very dilapidated structures [13-14]. For instance, in a news report, the Upper East Regional Directorate of the GES expressed worry at the alarming number of schools under trees and those in dilapidated conditions [10].

The Directorate of GES lamented that, for most schools in the rural areas, a cloud forming in the sky is a threat to academic work because the schools have to be closed for the safety of the teachers and pupils [10]. The situation causes these schools to lag behind, especially during the rainy seasons. Similarly, the external distraction of pupils' attention is very high when classes are held under trees as practised in several rural schools. Another challenge associated with holding classes under trees is the size of the chalkboard. The mobile chalkboards are usually very small in dimension, hence cannot contain enough chalkboard illustrations; not to talk of the display of teaching-learning materials (TLMs) [10].

With respect to teacher quality, according to GES [10], $71.1 \%$ of teachers at the JHS level in both public and private schools were trained with $28.9 \%$ untrained. The percentage of trained teachers in public JHS schools stood at $89.6 \%$ while that of the private JHSs is $18.7 \%$. However, private school pupils tend to perform better than public schools in the BECE over the years. While the country (Ghana) has over the years improved upon access to basic education in public schools, there are concerns about the poor BECE performance of pupils in government schools. Mills and Mereku [21], for example, explored pupils' achievement in national minimum standards and found that pupils in private schools performed better than those in government basic schools. Alhassan [22], in his work, also revealed that the pupils in private schools in Tamale Metropolis performed better than their counterparts in public schools for the 2013 BECE cohort. Similarly, Okyerefo, Fiaveh, and Lamptey [23] equally lamented over the poor performance of pupils in public schools from 2008 to 2010 . This abysmal performance of pupils in public schools relative to those in private schools may perhaps be due to the Ghana government's emphasis on access instead of quality [24]. It must be mentioned that quality determines how much and how well children learn and the extent to which their education translates into a range of personal, social and developmental benefits [5]. Thus, most pupils may find themselves in school but due to poor education delivery and quality, their achievement may be low.

\subsection{The Context of the Research}

Basic schools in the Central Region were the focus of this study due to three reasons. First, the Central region is one of 
the areas where pupils record an abysmally low performance in the BECE. In a report by the Ghana News Agency (GNA) [25], six schools in the Assin Central Municipality of the Central Region recorded zero percent in the 2015 BECE. The then Municipal Director of Education, in an interview with the Ghana News Agency at Assin Fosu, reported that out of the 148 candidates who sat for the examination in the six schools within the Central Region of Ghana, none qualified to be placed in senior high, technical or vocational schools [25]. In addition, Mills and Mereku [21] stated that about half of JHS pupils in the Effutu Municipality (Central Region) have not attained the minimum standard objectives as required by the mathematics curriculum. These issues called for concern to focus on basic schools in the region to study the trends of BECE performance. Secondly, basic schools in the Central Region of Ghana, have been one of the regions with a special case in terms of inadequate input and process factors in education; this distribution of resources is not uniform across rural and urban schools as well as public and private schools [20]. Could this affect the performance distribution of pupils in the BECE in the region?

Thirdly, earlier studies have documented pupils' attainment trends in BECE in most of the deprived regions, except for the Central Region. Research works have comprehensively discussed the BECE performance of pupils in the Northern Region [12-14], and Western Region [19]. Also, the performance distribution of pupils for school location (urban/rural) and school type (public/private) has not been well explored in the literature. In this research, we examined the BECE achievement trends of pupils in basic schools in the Central Region for a period of 5 years (2014-2018).

This research gives a clear picture of the performance trends in BECE using basic schools in the Central Region as a case. Such analyses have become critical in terms of understanding the nature of performance with regards to school context (i.e., urban, rural, public and private settings). This is to help stakeholders in education to make informed decisions and provide interventions for the schools with poor performance, bearing in mind the school location and type. This study also contributes to discourse in previous literature which helps to provide a foundation for future studies. Abreh, Owusu, and Amedahe [26], for example, examined performance trends in core mathematics and science at the SHS level. While their study is relevant, it only focused on two subjects at the SHS level. Contrary to this study, we looked at performance trends in BECE using the final year JHS pupils' best six grades (with Mathematics and English Language being compulsorily inclusive).

\subsection{Objectives}

1. The objectives of this research were to:

2. Explore the general BECE performance trends of JHS pupils from 2014-2018.

3. Understand the variations in BECE performance trends of JHS pupils based on school location (i.e., rural and urban).

4. Explore the variability in BECE performance trends of
JHS pupils based on school type (i.e., private and public).

\section{Methods}

\subsection{Research Design}

The descriptive exploratory design was employed for this study. This design was adopted because the study sought to explore the trend of pupils "performance in BECE with regards to urban, rural, public and private Junior High Schools within the Central Region of Ghana over five years (2014-2018) without any manipulation. The descriptive design mainly observes, describes, and documents aspects of a situation as it naturally occurs [27].

\subsection{School Selection}

The data comprised BECE results for public and private JHSs in all the 20 Metropolitan/Municipal/District Assemblies within the Central Region of Ghana. However, through stratification, six top-, middle-, and low-performing rural and urban districts were selected for the study. BECE results from the basic schools in the selected districts were requested, thereafter.

\subsection{Data Collection and Analysis Strategy}

Secondary data on pupils' performance for a period of five years $(2014-2018)$ in the BECE obtained from the GES was used in the conduct of the study. With this data, the proportion of pupils who passed successfully in the BECE was obtained. This was used as a measure of pupils' performance. The passing rate was determined using grades 1 to 5 . This, therefore, implies that pupils obtaining, at least, a grade of 5 in six subjects including English Language and Mathematics were considered to have passed the BECE successfully. This translates into aggregates 6 to 30 for a pass.

The data obtained were summarised using percentages, frequency counts and pictorial representations such as times series graphs. The description of the performance trends was done with respect to school location (rural/urban) and school type (private/public). The descriptions were done in this fashion because the unit of analysis in this study include school location and school type. The data focused on pupils who passed and those who failed as well. The criteria for a pass, according to GES, was grade 36 or better (i.e., grade 6 in 6 courses). Pupils who obtained grades worse than 36 were classified as those who have failed the examination.

\subsection{Ethical Considerations}

Ethical clearance for this research was granted by the Ethical Review Board (ERB) of the College of Education Studies, University of Cape Coast, Ghana, with the reference number CES-ERB/UCC-EDU/V3/19-14. The data obtained were password-protected to prevent other parties from having access to it [28]. Moreover, pseudonyms were used for the schools and thus, the analysis did not make reference to any specific school. The authors assured GES of confidentiality 
in using the data which were released for this paper. Consent (retrospective) was also sought before the data was used [29].

\section{Results}

\subsection{General Performance Trends from 2014 to 2018}

The general performance trends from 2014 to 2018 are presented in Table 1 and Figure 1, respectively.

Table 1. Pupils' General performance in BECE from 2014 to 2018.

\begin{tabular}{llll}
\hline Year & n & Passed (\%) & Failed (\%) \\
\hline 2014 & 2,583 & $1,936(71.49)$ & $647(28.51)$ \\
2015 & 2,652 & $1,812(61.17)$ & $840(38.83)$ \\
2016 & 2,594 & $1,676(62.44)$ & $914(37.56)$ \\
2017 & 2,561 & $1,784(67.50)$ & $777(32.50)$ \\
2018 & 2,655 & $1,966(70.49)$ & $689(29.51)$ \\
\hline
\end{tabular}

Source: Field Survey (2019).

$\mathrm{n}=$ Number of people who sat for the examination.
The data in Table 1 reveals that the number of pupils who sat for BECE from 2014 to 2018 range from 2,561 to 2,655. It appears that the proportion of pupils who passed in each year were more than those who failed. In 2014 for instance, 1,936 pupils out of 2,583 passed the examination. Similarly, 1,812 pupils out of 2,652 in 2015 passed, and 1,676 out of 2,594 passed in 2016. This trend follows the same pattern from 2017 to 2018.

Figure 1 presents the performance trends based on the proportions of pupils who passed from 2014 to 2018. For the five years under study, 2014 recorded the highest percentage of pupils who passed the BECE (71.49\%). No clear pattern of performance was found. The year 2015 saw a decrease in pass rate from the previous year (2014) from $71.49 \%$ to $61.17 \%$. There was a slight increase in pass rate to $62.44 \%$ in 2016 and further increased to $67.5 \%$ in 2017. The percentage of pupils who passed increased again to $70.49 \%$ in 2018 .

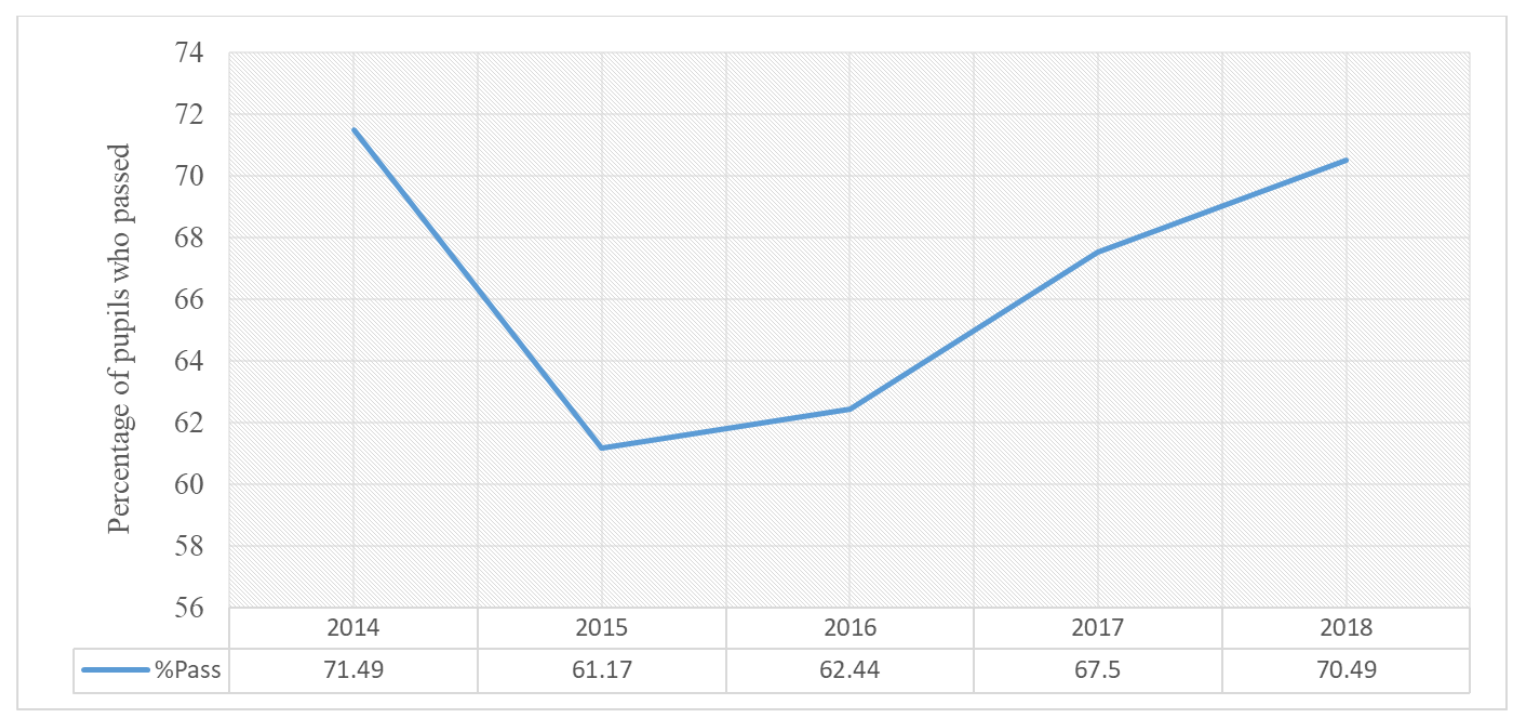

Figure 1. General performance trends in BECE from 2014-2018.

\subsection{BECE Performance Distribution Based on School Location}

The distributions of BECE performance based on the school location (rural/urban) are shown in Table 2 and Figure 2.

Table 2. Pupils' Performance in BECE based on School Location.

\begin{tabular}{|c|c|c|c|c|c|c|}
\hline \multirow{2}{*}{ Year } & \multicolumn{3}{|l|}{ Rural } & \multicolumn{3}{|l|}{ Urban } \\
\hline & $\mathrm{n}$ & Passed (\%) & Failed (\%) & $\mathbf{n}$ & Passed (\%) & Failed (\%) \\
\hline 2014 & 1,139 & $82(69.84)$ & $31(30.16)$ & 1,444 & $82(73.45)$ & $61(26.55)$ \\
\hline 2015 & 1,287 & $76(51.72)$ & $51(48.28)$ & 1,365 & $1,04(72.47)$ & $32(27.53)$ \\
\hline 2016 & 1,204 & 68 (58.59) & $51(41.41)$ & 1,390 & $99(67.04)$ & $39(32.96)$ \\
\hline 2017 & 1,239 & $77(61.61)$ & $46(38.39)$ & 1,322 & $1,00(74.53)$ & $31(25.47)$ \\
\hline 2018 & 1,211 & 87 (68.99) & $33(31.01)$ & 1,444 & $1,09(72.3)$ & $35(27.7)$ \\
\hline
\end{tabular}

Source: Field Survey (2019), Percentage in parentheses.

$\mathrm{n}=$ Number of people who sat for the examination.

Table 2 presents the BECE performance results of pupils in rural and urban schools. From 2014 to 2018, pupils who sat for BECE in the selected rural schools ranged from 1,204 to 1,287 , and those in the urban schools ranged from 1,322 to 1,444 . In general, the data suggested that more pupils in the urban than rural schools sat for BECE from 2014-2018. This translated into the proportion of pupils who passed the examination. Apart from the year 2014 that had an equal number of pupils from rural and urban schools who passed the examination, more pupils in urban schools passed the 
examination relative to those in rural schools. In 2015, for instance, 1,044 out of 1,365 pupils in urban schools passed BECE as opposed to 768 out 1,287 pupils from rural schools who sat for the examination. A similar distribution of performance was found in 2016, 2017, and 2018. Except for the year 2014 which saw more pupils from urban schools failing the examination, the performance pattern was different with the subsequent years (2015-2018). In 2015, 519 pupils (out of 1,287 ) and 321 pupils (out of 1,365) in rural and urban schools respectively failed the BECE.

Figure 2 further presents the trend analysis of the performance based on the school location. The graph displayed the proportion of pupils who passed the examination in both rural and urban schools. It is constructive to note that the trends in the BECE performance for pupils in rural schools appear to be different from pupils in urban schools. The results, as shown in Figure 2, suggest that for all the 5 years under investigation (2014-2018), the proportion of pupils who passed in rural schools were less than those who were in urban schools. In 2014, the proportion was $69.84 \%$ for rural schools, and $73.45 \%$ for urban schools. Equally, rural schools in 2015 recorded a
$51.72 \%$ pass rate whereas urban schools recorded a $72.47 \%$ pass rate.

From Figure 2, it appears no definitive trend was found for the BECE pass rate of pupils in rural schools and those in urban schools. For rural schools, the proportion of pupils who passed for the 5 consecutive years (2014-2018) were $69.84 \%, 51.72 \%, 58.59 \%, 61.61 \%$, and $68.99 \%$. In 2015 , the rural schools recorded a sharp decrease in the pass rate from $69.84 \%$ to $51.72 \%$. The year 2016 also saw an increase in pass rate from $51.72 \%$ to $58.59 \%$, and to $61.61 \%$ in 2017 and $68.99 \%$ in 2018 . Except for the decrease in pass rate from 2014 to 2015, the percentage of pupils who passed in rural schools progressively increased from 2015 to 2018. This progressive increase was still not up to the level of pass rate in urban schools.

For pupils in urban schools, the proportion of pupils who passed increased in some years and decreased in other years. The percentage of pupils who passed marginally decreased from $73.45 \%$ in 2014 to $72.47 \%$ in 2015 . The year 2016 saw a decrease in pass rate from $72.47 \%$ in 2015 to $67.04 \%$. The pass rate in 2017 , however, increased to $74.53 \%$ and later decreased to $72.3 \%$ in 2018 .

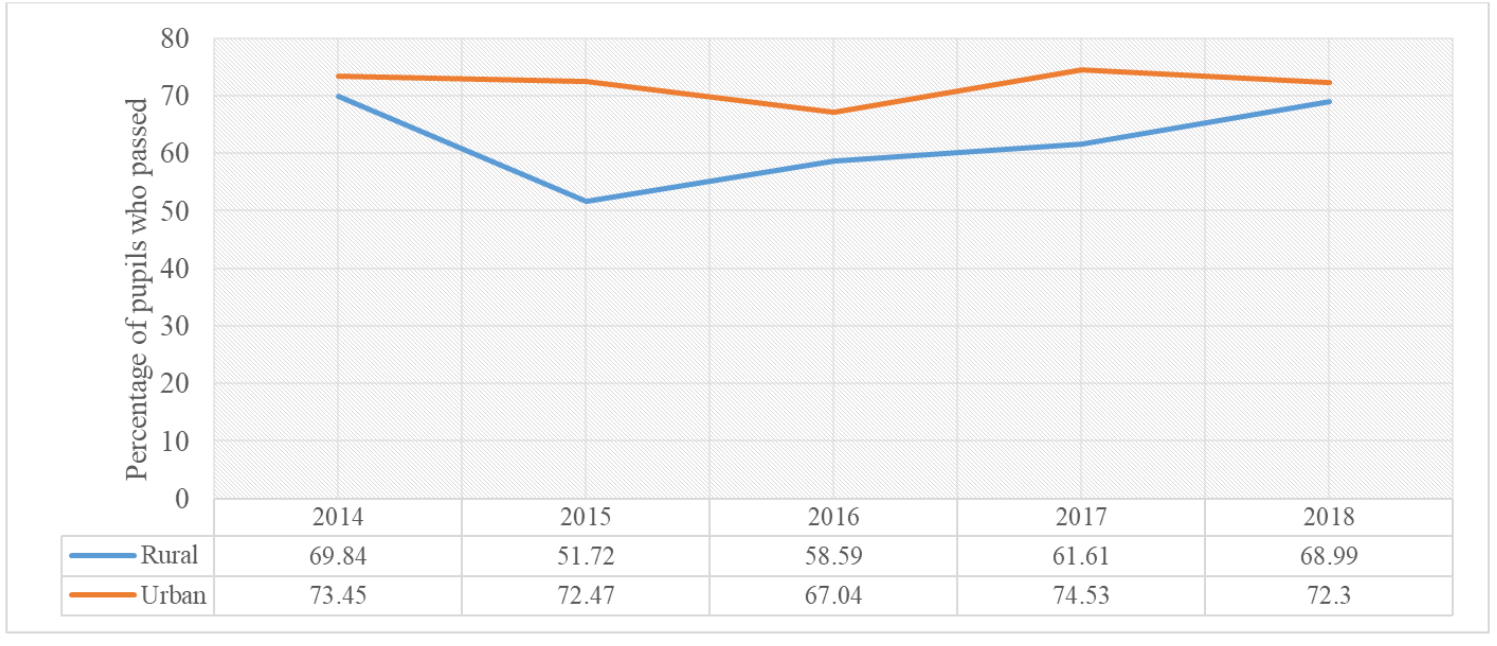

Figure 2. Trend analysis of BECE performance based on school location from 2014-2018.

\subsection{BECE Performance Based on School Type (Private \& Public)}

The study also presented the performance of pupils in BECE based on school type. The details are shown in Table 3 and Figure 3 accordingly.

Table 3. Trends in BECE Performance based on School Type.

\begin{tabular}{|c|c|c|c|c|c|c|}
\hline \multirow{2}{*}{ Year } & \multicolumn{3}{|c|}{ Private Schools } & \multicolumn{3}{|c|}{ Public Schools } \\
\hline & $\mathbf{n}$ & Pass (\%) & Fail (\%) & $\mathbf{n}$ & Pass (\%) & Fail (\%) \\
\hline 2014 & 540 & $41(75.51)$ & $13(24.49)$ & 2,043 & $1,52(70.41)$ & $51(29.59)$ \\
\hline 2015 & 514 & $36(58.3)$ & $15(41.7)$ & 2,138 & 1,44 (61.94) & $69(38.06)$ \\
\hline 2016 & 524 & $36(68.83)$ & $16(31.17)$ & 2,070 & $1,31(60.73)$ & $75(39.27)$ \\
\hline 2017 & 524 & $34(62.17)$ & $18(37.83)$ & 2,037 & $1,44(68.92)$ & $59(31.08)$ \\
\hline 2018 & 483 & $32(63.32)$ & $16(36.68)$ & 2,172 & $1,64(72.42)$ & $52(27.58)$ \\
\hline
\end{tabular}

Source: Field Survey (2019), Percentage in parentheses.

$\mathrm{n}=$ Number of people who sat for the examination.

The results in Table 3 depict that more than thrice the number of pupils who sat for BECE from 2014 to 2018 are from public schools. In 2014, for example, 1,526 pupils from public schools sat for the examination. In the same year, 540 
pupils from private schools sat for the examination. For 2015, 514 pupils who sat for BECE were from private schools whereas 2,138 of them were from public schools. The trend of performance was not so different for 2016,
2017, and 2018. More pupils from public schools than private schools passed BECE.

Figure 3 further provides more details of the trends in performance based on school type (private/public).

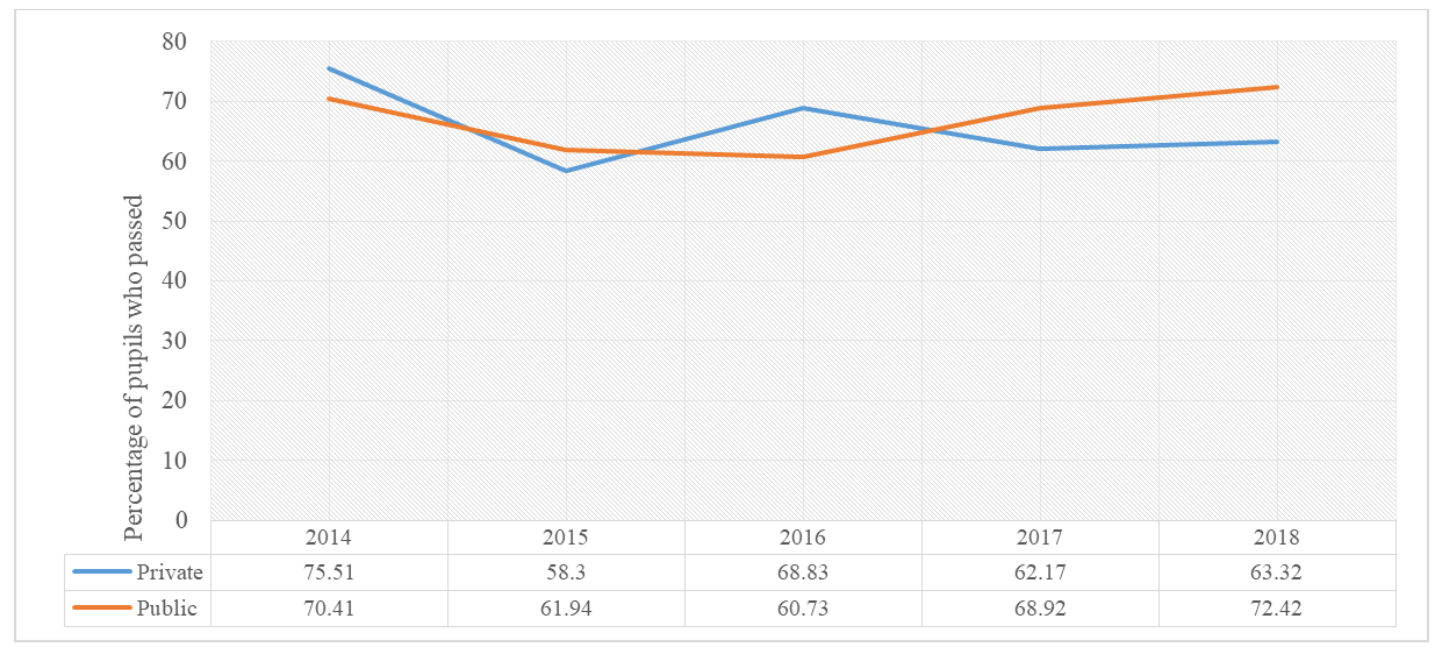

Figure 3. Trend analysis of BECE performance based on school type from 2014-2018.

Figure 3 shows no clear trend in the BECE performance of pupils based on school type. For private schools, the proportion of pupils who passed in 2014 was $75.51 \%$; this decreased to $58.3 \%$ in 2015 . This pass rate increased to $68.83 \%$ in 2016 , decreased to $62.17 \%$ in 2017 , and increased to $63.32 \%$ in 2018 . For pupils in public schools, the pass rate in 2014 was $70.41 \%$. This decreased to $61.94 \%$ and $60.73 \%$ in 2015 and 2016 respectively. The year 2017 saw a slight increase in the pass rate to 62.17 and further increased to $72.42 \%$ in 2018 . In some of the years, the pass rate was higher for pupils in private schools as compared to those from public schools. This story was different for some other years. In 2014 and 2016, for instance, more pupils from private schools than public schools passed the examination. This, however, was not the case in 2015, 2017, and 2018.

\section{Discussion}

The findings from this study revealed that, for most of the time, the percentage of pupils who passed the BECE in rural schools were significantly less than those who passed in urban schools. This result rekindles a debate and brings to bear different interpretations. The general geographic distribution and standard of living in rural and urban areas in the country are at the centre of this debate. In Ghana, urban areas are flooded with better jobs, state-of-the-art hospitals and schools, good roads, and potable drinking water; just to name a few. Locations marked as rural areas, on the contrary, do not have access to all these privileges. This disparity is also common in the education sector and this may explain why pupils in urban schools performed better in the BECE. Several scholars have supported and corroborated this claim of location disparity in terms of school conditions, infrastructure, teacher commitment, teaching and learning materials, internet access, and socio-economic status, among others where rural schools are often underprivileged $[13,14$, 18]. Findings from some of these previous studies have shown that it is common to find schools under trees in rural areas $[10,20]$ and in some instances, pupils would have to walk several miles before they get to the school.

The research found that, generally, more pupils from public schools than private schools passed BECE. This trend of results does not sound surprising for two reasons. First, the proportion of trained teachers (i.e., people who have gone through formal teacher preparation programme accredited by the government) in the private schools are far less than those in the public schools. This was confirmed by GES [10] who indicated that about $89.6 \%$ of teachers in the public schools are trained teachers whereas only $18.7 \%$ of private school teachers have gone through such training. The second reason is that public schools, particularly those located in the urban areas, are at the advantage of good infrastructure, conducive teaching and learning atmosphere, adequate instructional materials and, perhaps, sufficient funds from the government for running the school. The private schools rather depend solely on the fees paid by the pupils to run the school. The introduction of the free basic and senior high school introduced by the government of Ghana, for example, led to the collapse and interruptions in most of the private schools. This, for many private schools, was due to insufficient funds because most parents withdrew their wards from such schools.

This study's finding that public schools generally performed better in BECE as compared to private schools, appears to contradicts that of earlier scholars. Studies by Alhassan [22] and Okyerefo et al. [23] observed that pupils in private schools performed better in BECE than their colleagues in public schools. These authors, however, conducted their studies using data from different years; 
Alhassan [22] used the 2013 BECE year group while Okyerefo et al. [23] used data from 2008 to 2010. The discrepancies in the findings of this research and previous studies can be explained by the differences in the years used for the analysis in the respective studies.

\section{Conclusion and Recommendations}

The study, based on the outcome, concluded that urban schools, as well as public schools, performed better in the BECE, at least for the period understudied. This speaks to the fact that schools found in urban areas as compared to those in the rural areas may be having an advantage in terms of the input and process factors needed to achieve better performance. This is also applicable to schools that are owned by the government. Although the finding from this study is a starting point, it must be interpreted with caution since only 5 years of data were explored. The finding calls for a relook at the resource distribution and general monitoring of the educational quality across the country. In fact, the performance gap based on some geographical and school-ownership status needs to be bridged since all pupils are citizens who deserve better irrespective of where they find themselves in the educational structure.

The study recommended that since pupils in urban schools performed better in the BECE than those in rural schools, the MoE, GES, and other stakeholders in the area of education are encouraged to ensure equitable distribution of resources in terms of infrastructure, teaching and learning resources, adequate and competent teachers to both urban and rural schools to promote the enhancement of pupils' performance in BECE in rural schools. Also, headteachers and administrators of private schools are encouraged to solicit ideas from the administrators of public schools regarding the strategies to adopt in their quest to improve the pupils' performance in the BECE. This study also suggested that future studies should conduct ecological analysis of schools found in rural areas.

\section{References}

[1] Abreh, M. K. (2017). Involvement of school management committees in school-based management: Experiences from two districts of Ghana. Educational Planning, 24, 61-75.

[2] United Nations Economic and Social Commission for Asia and the Pacific [UN ESCAP] (2015). Statistical Yearbook for Asia and Pacific 2015, SDG 4. Retrieved from https://www.unescap.org/ sites/default/files/SYB2015_Full_Publication.pdf

[3] Bruns, B., Mingat, A., \& Rakotomalala, R. (2003). A chance for every child: Achieving universal primary education by 2015. Washington, DC: World Bank.

[4] Akinbote, O. (2001). The Nigerian primary school teachers: Angels of instruction or devils of destruction. Nigerian Journal of Educational Philosophy, 7 (1), 35-40.
[5] United Nations Educational, Scientific and Cultural Organisation [UNESCO] (2005). Cultural heritage, creativity and education for all in Africa; for education in the arts and creativity in primary and secondary schools. Regional Conference on Arts Education, Port Elizabeth, South Africa.

[6] World Bank. (2004). Monitoring and evaluation: Some tools methods and approaches. Retrieved from http://www.worldbank.org/oed/ecd/.

[7] Ministry of Education (2003) Education Strategic Plan 20032015: Policy, strategy and targets - Volume 1. Accra, Ghana: Ministry of Education.

[8] Adu-Gyamfi, S., Donkoh, W. J., \& Addo, A. A. (2016). Educational reforms in Ghana: Past and present, Journal of Education and Human Development, 5 (3), 158-172.

[9] Quainoo, E. A., Quansah, F., Adams, F., \& Opoku, E. (2020). Comparative review of educational reforms, policies, and systems: A case of China and Ghana. Journal of Comparative Studies and International Education (JCSIE), 2 (1), 5-22.

[10] Ghana Education Service (2016). Education sector performance report. Retrieved from https://www.google.com/url.

[11] Ansah A. (2017). A descriptive assessment of higher education access, participation, equity, and disparity in Ghana. Retrieved from http://sgo.sagepub.com/content/

[12] Abdallah, H., Fuseini, M. N., Abudu, A. M., \& Nuhu, Y. (2014). Dilemma of basic school pupils in Northern Ghana with respect to their learning context. Education Research International, 1 , http://dx.doi.org/10.1155/2014/140737

[13] Adamoah, Y. K., \& Acquah, J. (2016). Determinants of students' performance in basic education certificate examination (BECE) in the Upper East Region of Ghana: A case study of Kassena-Nankana West District (KNWD). American Journal of Research Communication, 4 (10), 91107.

[14] Amuzu, S., Ankalibazuk, A., \& Abdulai, S. I. (2017). Low performance of pupils in BECE: A case study of Sagnarigu District in Northern Region, Ghana. International Journal of Advance Research in Science, Engineering and Technology, 4 (7), 4176-4184.

[15] Ankoma-Sey, V. R., Asamoah, D., Quansah, F., \& Aheto, S. K. (2019). Factors affecting junior high school pupils' performance in mathematics in Cape Coast Metropolis, Ghana. Staff and Educational Development International, 24 (3), 120-129.

[16] Ansah, J. K., Quansah, F., Nugba, R. M. (2020). 'Mathematics Achievement in Crisis': Modelling the influence of teacher knowledge and experience in senior high schools in Ghana. Open Education Studies, 2, 265-276. https://doi.org/10.1515/edu-2020-0129

[17] Fletcher, J. (2018). Performance in Mathematics and Science in basic schools in Ghana. Academic Discourse: An International Journal, 10 (1), 1-18.

[18] Gyan, C., Mabefam, M. G., \& Baffoe, M. (2014). Push out or drop out? Taking a critical look at the poor and drop-out of students of the JSS/JHS programme in Ghana. Academic Journal of Interdisciplinary Studies, 3 (1), 409-420. 
[19] Mohammed, F., Asare-Bediako, M., \& Aboagye, P. (2016). Factors contributing to the low academic achievement of students at the basic education certificate examination in some public junior high schools of a political district in the Western Region of Ghana: Students' and teachers' perspective. International Journal of Mathematics and Statistics Studies, 4 (3), 1-10.

[20] Nugba, R. M. (2021). The status of educational input factors in junior high schools in the Central Region of Ghana. American Journal of Education and Learning, 6 (1), 50-63.

[21] Mills, E. D., \& Mereku, D. K. (2016). Students' performance on the Ghanaian junior high school mathematics national minimum standards in the Effutu Municipality. African Journal of Educational Studies in Mathematics and Sciences, $12,25-34$.

[22] Alhassan, I. (2016). A comparative assessment of the academic performance among public and private junior high schools in the Tamale Metropolis of Ghana. A thesis submitted to the Department of Planning, Kwame Nkrumah University of Science and Technology, Ghana.

[23] Okyerefo, M. P. K., Fiaveh, D. Y., \& Lamptey, S. N. L. (2011). Factors prompting pupils' academic performance in privately owned junior high schools in Accra, Ghana. International Journal of Sociology and Anthropology, 3 (8), 280-289.

[24] Ampiah, J. G. (2010). Quality basic education in Ghana: Prescription, praxis and problems. Paper delivered at the Experience Sharing Seminar, Accra, Ghana.

[25] Ghana New Agency (2015). 6 schools scored 0\% in BECE in the Central Region. Retrieved from https://newsghana.com.gh/6-schools-scored-0-in-bece/

[26] Abreh, M. K., Owusu, K. A., Amedahe, F. K. (2018). Trends in performance of WASSCE candidates in the science and mathematics in Ghana: Perceived contributing factors and the way forward. Journal of Education, 198 (1), 113-123.

[27] Amedahe, F. K., \& Asamoah-Gyimah, K. (2015). Introduction to educational research. Cape Coast: UCC Printing Press.

[28] Tripathy, J. P. (2013). Secondary data analysis: Ethical issues and challenges. Iranian Journal of Public Health, 42 (12), 1478-1479.

[29] Jol, G., \& Stommel, W. (2016). Ethical considerations of secondary data use What about informed consent? Dutch Journal of Applied Linguistics, 5 (2), 180-195. 